\title{
Clivus pathologies from diagnosis to surgical multidisciplinary treatment. Review of the literature
}

\author{
Patologie del clivus dalla diagnosi al trattamento chirurgico multidisciplinare. \\ Revisione della letteratura \\ Fabio Pagella ${ }^{1,2}$, Sara Ugolini',2, Cesare Zoia ${ }^{3}$, Elina Matti ${ }^{1}$, Paolo Carena ${ }^{1}$, Roberta Lizzio ${ }^{1}$, Marco Benazzo ${ }^{1,2}$ \\ ${ }^{1}$ Department of Otorhinolaryngology, Fondazione I.R.C.C.S. Policlinico San Matteo, Pavia, Italy; ${ }^{2}$ Department of \\ Otorhinolaryngology, University of Pavia, Italy; ${ }^{3}$ Neurosurgery Unit, Fondazione I.R.C.C.S. Policlinico San Matteo, Pavia, Italy
}

\begin{abstract}
SUMMARY
The Clivus is a bone that lies in a central position of the skull base, and it is a crucial point that splits and connects different anatomical compartments at the same time. There is significant variability of diseases involving the clivus, from neoplasms to non-neoplastic, inflammatory or traumatic lesions. Each of these is rare in frequency, and this heterogeneity contributes to yield the management even more challenging. Clival pathologies can be asymptomatic or have manifestations ranging from aspecific headache to cranial nerves palsies, till life-threatening complications as cerebrospinal fluid rhinorrhoea, meningitis or brain abscess. There isn't an univocal endorsement among experts with regard to the best approaches to manage the clivus. The paths described are many, the main division is between the transclival and transcranial lateral approaches. We performed a review of the literature, thus highlighting how authors seem to suggest that the surgical approach shouldn't be chosen aprioristically, but based on a patient centred analysis, considering the combination of multiple surgical corridors. From diagnosis to surgery and medical therapy, clival pathologies require a team of multidisciplinary experts to ensure the best standard of treatment and higher survival rate.
\end{abstract}

KEY WORDS: clivus, clival pathology, transclival approach, transcranial approach, skull base surgery

\section{RIASSUNTO}

Il Clivus è localizzato in sede centrale nella base cranica, rappresentando uno snodo cruciale, che separa e collega diversi comparti anatomici. Le patologie che coinvolgono il clivus sono eterogenee: da neoplasie a lesioni non neoplastiche, infiammatorie o traumatiche. Tutte queste sono rare per insorgenza e ciò contribuisce a renderne impegnativo il trattamento. Le patologie clivali possono mantenersi asintomatiche oppure manifestarsi con sintomi che vanno dalla cefalea, alla paralisi di nervi cranici, fino a complicanze potenzialmente letali come, rinoliquorrea, meningite e ascessi cerebrali. Gli esperti non sono sempre concordi riguardo al tipo di approccio chirurgico con cui trattare il clivus. Le vie descritte sono molteplici, principalmente distinte tra approcci transclivali e approcci transcranici laterali. A oggi, dopo una revisione della letteratura, si conclude che la programmazione chirurgica non deve essere scelta a priori, ma con un accurato studio del singolo caso clinico, valutando la combinazione di più corridoi chirurgici, se necessario. Dalla diagnosi alla chirurgia, alla terapia medica, la gestione delle patologie clivali richiede un team multidisciplinare di esperti, tale da garantire la migliore qualità nel trattamento e il più alto tasso di sopravvivenza.

PAROLE CHIAVE: clivus, patologia clivale, approccio transclivale, approccio transcranico, chirurgia del basicranio

\section{Introduction}

In the early 1990s, Samii and Knosp defined the clivus "no man's land" due to the difficulty of accessing it ${ }^{1}$. Today we can say that the clivus would be
Received: September 8, 2020

Accepted: January 9, 2021

Correspondence

Fabio Pagella

Department of Otorhinolaryngology, Fondazione I.R.C.C.S. Policlinico San Matteo, Pavia, Italy

E-mail: tpagella@libero.it

Funding

None.

Conflict of interest

The Authors declare no conflict of interest.

How to cite this article: Pagella F, Ugolini S, Zoia $\mathrm{C}$, et al. Clivus pathologies from diagnosis to surgical multidisciplinary treatment. Review of the literature. Acta Otorhinolaryngol Ital 2021;41(SUPPL.1):S42-S50. https://doi. org/10.14639/0392-100X-suppl.1-41-2021-04

(C) Società Italiana di Otorinolaringoiatria e Chirurgia Cervico-Facciale

\section{(c) (1) $(9)$}

This is an open access article distributed in accordance with the CC-BY-NC-ND (Creative Commons Attribution-NonCommercial-NoDerivatives 4.0 International) license. The article can be used by giving appropriate credit and mentioning the license, but only for non-commercial purposes and only in the original version. For further information: https:// creativecommons.org/licenses/by-nc-nd/4.0/deed.en 
better called "res in commune multorum", because we are well aware that, due to the variety and the rarity of clival pathologies, the key to a better outcome for the patient is to bring together the expertise of different specialists. Each clinical case should be evaluated by the otorhinolaryngologist together with a multidisciplinary team. In this review we will focus on clival pathologies that require a surgical treatment, which always foresees the collaboration between otorhinolaryngologist and neurosurgeon.

The Clivus is indeed a crucial point that splits and connects different anatomical compartments at the same time. It is a bone that lies in a central position of the skull base, being a boundary between endocranial structures and maxillofacial and neck regions. One of the first scientists that undertook studies involving the clivus was the German Johann Friedrich Blumenbach (1752-1840) that gave name to the bone, therefore called Clivus Blumenbachii. Other neuroanatomists that have to be mentioned are Wenzel Leopold Gruber (1814-1890) who observed the Grubers's ligament, Primo Dorello (1872-1963) for the so-called Dorello's canal and Johann Friedrich Meckel, the first that described the condylus tertius in 1815 .

\section{Embryology and anatomy}

The clivus originates from the neurocranium and particularly from the chondrocranium ${ }^{2}$, which is formed initially by several separate cartilages (i.e. ossification centers) that will fuse and ossify to form the skull base, after cranial nerves and blood vessels have developed ${ }^{3}$. The basisphenoid and basiocciput, formed from the four primary occipital sclerotomes or "vertebrae" (O1-O4) ${ }^{2}$, are separated before fusion by the sphenoccipital synchondrosis. Complete ossification of the synchondrosis takes place at the age of 13 to 18 years in males and 12 to 16 years in females ${ }^{4}$.

The clivus (Blumenbachii) is the central element of the skull base and is about 4 to $5.5 \mathrm{~cm}$ long and about $3 \mathrm{~cm}$ wide at its midpoint. The midsagittal section of the clivus clearly presents a wedge-shaped appearance with a thin posterior and thick anterior part. Inside a spongy structure identifies the content of bone marrow. The osseous slope of the clivus slants upward and forward from the anterior aspect of the foramen magnum to the dorsum sellae and the posterior clinoid processes. The sphenoid sinus pneumatization may extend to the clivus with a posterior recess, and rarely this involves the whole clivus. From a caudal view, the anterior margin of the clivus is bordered by the vomer with its alae. Lateral to the clivus is the petro-occipital fissure housing the inferior petro-occipital vein, connecting the cavernous sinus to the internal jugular vein. Cranially, the inferior petrous sinus rests on the petrooccipital fissure and creates the sulcus sinus petrosi inferioris. The lateral borders of the clivus are related to cranial nerves V through XII, the internal jugular veins, and the inferior petrosal sinuses and the foramen lacerum in the anterior part ${ }^{4}$. The posterior endocranial surface is smooth and composed of cortical bone. It is covered with dura mater, which is perforated by the abducens nerves, coming from its cisternal portion, in the central part of the clivus ${ }^{2}$. The medulla oblongata and pons lie adjacent to the posterior surface of the clivus, but are separated by the prepontine and perimedullary cisterns ${ }^{4}$. Several ligaments cross the gap between the petrous apex and the lateral margin of the dorsum sellae, among these the petrosphenoidal or Gruber's ligament is important for the course of the abducens nerve that passes through the foramen sphenopetrosum (fibrosum or osseum) and is fixed with its dural sheath at the superior margin of the petrous pyramid. This narrow passage for the abducens nerve is known as Dorello's canal, though it is actual knowledge that it is not a real canal ${ }^{5}$. The tectorial membrane and superior longitudinal band of the cruciate ligament both attach to the posteroinferior surface of the clivus. The fibrous raphe of the pharynx (superior pharyngeal constrictor muscle), longus capitus, rectus capitus anterior, and the anterior atlantooccipital membrane are found in connection to the inferior exocranial surface of the clivus. The outer surface of the clivus is covered in thick fibrous tissue which is a continuation of the fibrocartilago basalis of the foramen lacerum.

The arterial supply of the clivus is primarily derived from two vessels: a branch off the internal carotid artery, the meningohypophyseal trunk, and a branch of the ascending pharyngeal artery, the posterior meningeal artery. Dorsal to the clivus, the basilar artery and basilar venous plexus are found and can create faint grooves on the bone ${ }^{4}$.

\section{Pathologies}

There is great variability of diseases involving the clivus, of different nature, and each rare in frequency. This heterogeneity contributes to yield the management even more challenging (Tab. I). Clival pathologies can be asymptomatic or have manifestations ranging from aspecific headache to cranial nerves palsies, visual problems, endocrinopathy (if the sella is involved), till life-threatening complications as cerebrospinal fluid (CSF) rhinorrhoea and episodes of meningitis or brain abscess.

\section{Neoplastic pathologies}

Among clival tumors, the most frequent are chordomas. Chordoma is a rare cancer that accounts for $1-4 \%$ of all bone malignancies. The incidence is of 0.08 per 100.000 , 
F. Pagella et al.

Table I. Multidisciplinary management for clival pathologies.

\begin{tabular}{|c|c|c|c|}
\hline Pathology & Surgery & $\begin{array}{l}\text { Multidisciplinarity } \\
\text { between surgeons }\end{array}$ & $\begin{array}{l}\text { Other specialists } \\
\text { involved }\end{array}$ \\
\hline Fibrous dysplasia & Biopsy + / decompression & $\begin{array}{l}\text { ENT surgeon +/- } \\
\text { neurosurgeon }\end{array}$ & / \\
\hline Neurenteric cyst & Removal & $\begin{array}{l}\text { ENT surgeon +/- } \\
\text { neurosurgeon }\end{array}$ & / \\
\hline Ecchordosis physaliphora & $\begin{array}{c}\text { Removal + } \\
\text { skull base plasty }\end{array}$ & $\begin{array}{l}\text { ENT surgeon + } \\
\text { neurosurgeon }\end{array}$ & / \\
\hline Epidermoid & Removal & $\begin{array}{c}\text { ENT surgeon + } \\
\text { neurosurgeon }\end{array}$ & / \\
\hline Cholesterol granuloma & Marsupialization & $\begin{array}{c}\text { ENT surgeon +/- } \\
\text { neurosurgeon }\end{array}$ & / \\
\hline Sphenoid mucocele & Marsupialization & $\begin{array}{l}\text { ENT surgeon +/- } \\
\text { neurosurgeon }\end{array}$ & / \\
\hline Chordoma & Removal with ETCA / MTCA / combined & $\begin{array}{l}\text { ENT surgeon + } \\
\text { neurosurgeon }\end{array}$ & $\begin{array}{l}\text { Radiotherapist } \\
+/ \text { - oncologist }\end{array}$ \\
\hline Chondrosarcoma & Removal with ETCA / MTCA / combined & $\begin{array}{c}\text { ENT surgeon + } \\
\text { neurosurgeon }\end{array}$ & Radiotherapist \\
\hline Meningioma & Removal with ETCA / MTCA / combined & $\begin{array}{l}\text { ENT surgeon + } \\
\text { neurosurgeon }\end{array}$ & $\begin{array}{l}\text { Radiotherapist } \\
+/ \text { - oncologist }\end{array}$ \\
\hline Metastasis & Biopsy & $\begin{array}{l}\text { ENT surgeon + } \\
\text { neurosurgeon }\end{array}$ & $\begin{array}{l}\text { Radiotherapist } \\
+/ \text { - oncologist }\end{array}$ \\
\hline Tumors of adjacent compartments & $\begin{array}{l}\text { Biopsy / } \\
\text { rescue surgery }\end{array}$ & $\begin{array}{c}\text { ENT surgeon + } \\
\text { neurosurgeon }\end{array}$ & $\begin{array}{l}\text { Radiotherapist } \\
+/ \text { - oncologist }\end{array}$ \\
\hline Plasmocytoma & $\begin{array}{l}\text { Biopsy / } \\
\text { rescue surgery }\end{array}$ & $\begin{array}{l}\text { ENT surgeon +/- } \\
\text { neurosurgeon }\end{array}$ & $\begin{array}{l}\text { Radiotherapist } \\
+/ \text { - hematologist }\end{array}$ \\
\hline $\begin{array}{l}\text { Osteomyelitis and } \\
\text { Osteoradionecrosis }\end{array}$ & Debridement & $\begin{array}{c}\text { ENT surgeon + } \\
\text { neurosurgeon }\end{array}$ & Infectious disease specialist \\
\hline CSF leak and meningocele & Skull base plastic & $\begin{array}{c}\text { ENT surgeon +/- } \\
\text { neurosurgeon }\end{array}$ & I \\
\hline Traumatic lesion & $\begin{array}{l}\text { Decompression + / } \\
\text { skull base plastic }\end{array}$ & $\begin{array}{c}\text { ENT surgeon + } \\
\text { neurosurgeon +/- } \\
\text { maxillofacial surgeon }\end{array}$ & / \\
\hline Craniovertebral junction disease & $\begin{array}{c}\text { Anterior odontoidectomy + } \\
\text { decompression }\end{array}$ & $\begin{array}{l}\text { ENT surgeon + } \\
\text { neurosurgeon }\end{array}$ & / \\
\hline
\end{tabular}

ENT: ear nose throat; ETCA: endoscopic transnasal transclival approaches; MTCA: microsurgical transcranial approaches; CSF: Cerebrospinal fluid.

with predominance in men and peak incidence between 50-60 years of age; chordomas rarely affect children and adolescents $\left(<5 \%\right.$ of all chordoma cases) ${ }^{6}$. These tumors are thought to arise from the transformed remnants of the notochord. Actual data suggest they are almost equally distributed among the three sites of the skull base, mobile spine, and sacrum ${ }^{7}$. Although slow-growing and histologically low grade, chordomas are locally invasive and have a high recurrence rate, making their clinical progression similar to malignant tumors ${ }^{8}$. They are not typically metastatic on presentation, but the often late-stage diagnosis of the disease makes distant metastasis more likely. In 5\% of chordomas there are metastasis to the lungs, bone, skin, and brain at the time of initial presentation. Because of the notochordal origin of these tumors, chordomas are midline entities; thus, in contrast to chondrosarcomas, they tend to grow from the midline, expanding posteriorly and laterally. At CT, clival chordoma appears as a midline soft-tissue lesion with bone destruction. The margin between the tumor and normal bone is usually non-sclerotic and sharp. Radiodensities are frequently present and are thought to represent remaining fragments of the destroyed clivus rather than new matrix formation. At MRI, they are usually hypo- to isointense on T1-weighted imaging, with cystic components that may contain protein or haemorrhage, giving them a bright signal. On T2-weighted images, they are characteristically of high signal. However, poorly differentiated chordomas have low T2 signal intensity. The enhancement pattern is variable: heterogeneous enhancement is more common than a homogeneous pattern ${ }^{8}$. 
The second tumor that may involve the clivus is chondrosarcoma, that account for $6 \%$ of skull-base tumors. Chondrosarcomas develop from primitive mesenchymal cells in synchondroses of the skull base with a high predilection for the petroclival synchondrosis. Therefore they are paramedian lesions that often expand not only into the clivus and sphenoid sinus but also into the middle and posterior cranial fossae, as well as the upper cervical area. The mean age of presentation of chondrosarcoma is 40 years ${ }^{8}$. With their usually slow growth rate, they are capable of reaching sizable dimensions, promoting bone erosion and significant displacement of neurovascular structures before causing symptomatology. Despite this local aggressiveness, these lesions often spare the dura, compressing and displacing rather than transgressing it ${ }^{9}$. Bone destruction and calcification occur in about $50 \%$ of chondrosarcomas and low-grade tumors tend to have more extensive calcification. These tumors are generally low-to-intermediate signal on T1-weighted images and high signal on fluid-attenuated inversion recovery (FLAIR), and T2-weighted images. Stippled foci of calcification, a hallmark of this tumor, may be demonstrated as heterogeneous areas of low signal within the tumor.

Meningiomas are another type of tumor that also affects the clival region. They represent the most frequent primary central nervous system tumors and they are considered benign lesions with favorable survival rates; however, on occasion, they may have a high-grade subtype, associated with a poor prognosis and higher risk for metastasis. Petroclival meningiomas are defined as being located medial to the exit of the trigeminal nerve. Some clival meningiomas are entirely dural and subdural, but others may have a tendency to involve the extradural and osseous compartments ${ }^{10}$. A non-contrast CT scan shows that these lesions have either a high- or low-attenuation signal compared with the surrounding brain. Hyperostosis, increased vascular markings and calcification are characteristic findings of meningiomas on $\mathrm{CT}$; however, malignant meningiomas can be more destructive of bony structures and more invasive of soft tissue ${ }^{11}$.

In the chapter of clival malignancies, it is important to mention also metastatic tumors. In patients with known cancer, the probability of a mass lesion in the clivus being a metastasis is high. The most common primary sites are prostate, kidney, liver (HCC), thyroid, gastrointestinal tract (adenocarcinoma), breast, lung, melanoma and lymphoma ${ }^{12,13}$. Metastasis may be low signal on T2 and this potentially differentiates them from chordomas and chondrosarcomas ${ }^{14}$. Furthermore, plasmacytoma is exceptionally reported in the clivus ${ }^{15}$. These lesions tend to enhance homogeneously on imaging; on T1-weighted MRI they are isointense or hy- pointense, but hyperintense on T2. Plasmacytoma can show cavernous sinus invasion, carotid encasement, sphenoid sinus invasion and suprasellar extension ${ }^{16}$.

Finally the clivus is prone to be involved in a variety of tumors of nearby structures: the dorsal extension of an invasive pituitary adenoma, trigeminal schwannomas may extend to the clivus leading to scalloping of its laterodorsal surface, even tumors arising from the jugular foramen or cerebellopontine cistern rarely extend as far as the clivus. Nasopharyngeal carcinomas (NPC) from their origin site can directly invade the adjacent basisphenoid and basiocciput.

\section{Non-neoplastic pathologies}

Most of the non-neoplastic occupying-space lesions develop with a clival bone resorption. One is the neurenteric cyst, a congenital lesion that may occur along the neural tube, which is formed by a failure of separation between endoderm and ectoderm in utero. The lesion is hyperintense (relative to grey matter) on T1-weighted and iso-intense to hypo-intense on T2-weighted MRI ${ }^{10}$. Another one is the cholesterol granuloma, rarely reported in literature involving the clivus ${ }^{17}$ (Fig. 1).

Histologically, it is characterized by chronic inflammation, fibrous tissue reaction, cholesterol crystals and foreign

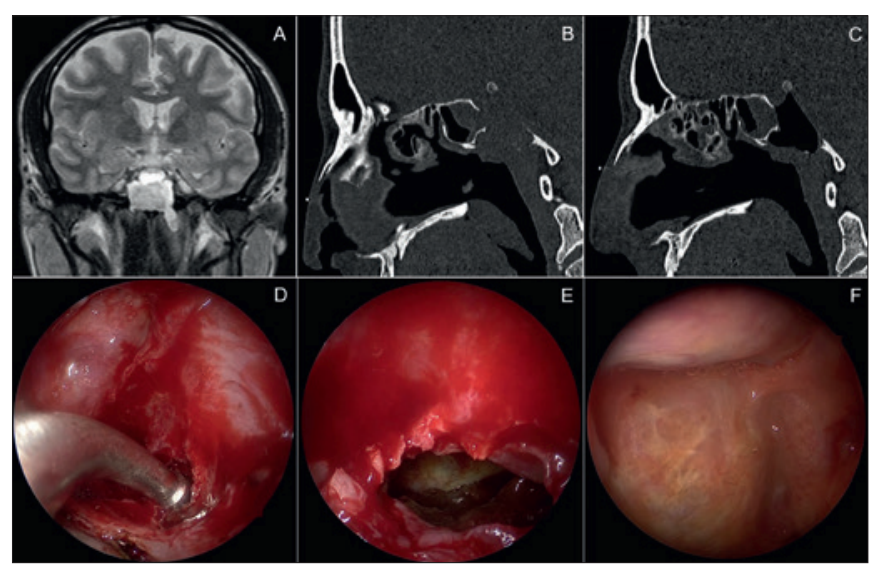

Figure 1. Images of a 46 years-old man who developed headache and photophobia due to a cholesterol granuloma. MRI revealed a sphenoid-clival growing lesion, with regular margins and $45 \mathrm{~mm}$ of diameter. The mass was hyperintense on $\mathrm{T} 1(\mathbf{A})$, iso-hyperintense on $\mathrm{T} 2$ and determined an elevation of the pituitary gland, with no signs of infiltrations of surrounding structures. A basal CT confirmed the presence of osteolysis of the posterior sphenoidal wall replaced by a mass of $29 \times 30 \mathrm{~mm}$ (B). Swelling of the nasopharyngeal roof was seen, through nasal endoscopy. An endoscopic transsphenoidal approach was made to reach the posterior sphenoidal wall where the cystic lesion was drained (D, E), with no sign of CSF leak. Postoperative endoscopic view with sella and ICAs visible through the thin clival bone left (F). A CT control 24 hours later showed no postoperative complications (C). 
body giant cells ${ }^{18}$. The pathogenesis is controversial and can be potentially explained by either the obstruction-vacuum theory or ex-posed marrow hypothesis ${ }^{19}$. On CT it appears as a smoothly marginated expansile lesion isodense with the brain tissue and non-enhancing. On MRI, distinction from petrous bone cholesteatoma is usually possible as cholesterol granulomas show a typical hyperintense signal on $\mathrm{T} 1{ }^{20}$. Also, sphenoid mucocele can result in bony resorption and sometimes erosion of the clivus. Mucoceles demonstrate variable densities at $\mathrm{CT}$ and signal intensities at MRI depending on their protein content and presence of associated infection. Rim enhancement may be seen as a hallmark of encapsulation ${ }^{8}$.

On the contrary fibrous dysplasia rise from the clivus where the mature bone becomes replaced with a weaker substitute of woven bone and fibrous tissue. This is a benign skeletal anomaly that affects one or multiple bones, with a greater tendency to affect long bones, ribs, and craniofacial bones. The lesions at CT images show a ground-glass appearance, while at T1-weighted MRI show low signal intensity, and T2-weighted MRI signal intensity varies from high to intermediate or low based on cellularity, collagen, bone, and cystic content of the lesion ${ }^{21}$.

Another clival congenital lesion is ecchordosis physaliphora. It consists of nodules of gelatinous tissue and it is considered to be an ectopic notochord remnant along the craniospinal axis, at the level of the clivus and sacrum ${ }^{22}$. Radiological typical findings are hypointensity in T1weighted and hyperintensity in T2-weighted MRI, and, most crucially, ecchordosis physaliphora shows no contrast enhancement after the administration of gadolinium ${ }^{23}$.

Epidermoids of the central nervous system consist of epidermal and connective tissue, usually in the form of a sac, characterized by slow growth. They tend to expand and spread along normal cleavage planes and thus they usually occupy more than one intracranial compartment. They have irregular "scalloped" margins and also tend to envelop vital neurovascular structures. Epidermoids may be mistaken for arachnoid cysts. Both lesions are non-enhancing and are hypointense on T1-weighted and hyperintense on T2weighted images, but, unlike arachnoid cysts, epidermoids have a slightly hyperintense segment when compared to $\mathrm{CSF}^{20}$.

The principal inflammatory pathology that may involve the clivus is skull base osteomyelitis. Most of the times it follows external ear infection in diabetic, old or otherwise immunocompromised patients, mostly males and has Pseudomonas aeruginosa as the usual pathogen. Patients usually present with ear pain and otorrhea. Skull base osteomyelitis is potentially life-threatening. Imaging is of paramount importance in establishing the diagnosis and CT findings are

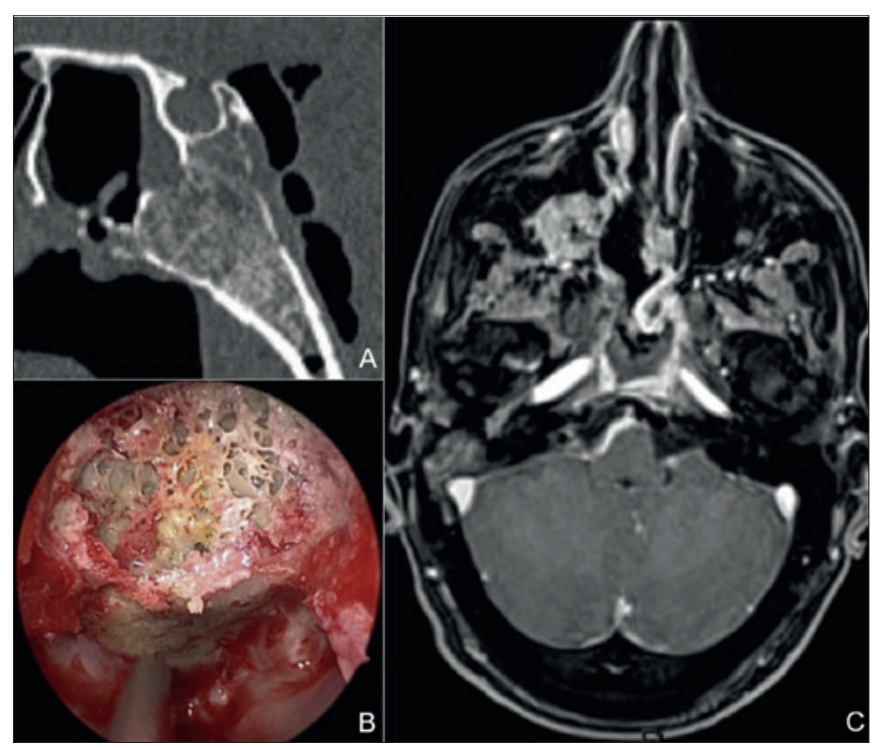

Figure 2. Images of a 36 years-old man who developed general disorientation, progressive tendency to drowsiness, cephalea, fever and aqueous rhinorrhea ${ }^{26}$. Four years before he was treated for undifferentiated NPC with a left-side modified radical neck dissection and elective chemo-radiotherapy, then a second line stereotactic radiotherapy (Cyberknife) for local relapse. At the time of admission CT scan revealed the presence of massive tension pneumocephalus with an erosion of infero-posterior parts of sphenoidal sinus and possible radionecrosis of the clivus (A). Nasal endoscopy revealed the presence of necrotic bone in the paramedian portion of the nasopharynx and active CSF rhinorrhea. The patient underwent endoscopic endonasal debridement of necrotic bone (B) and repair of the clival fistula with a pedunculated nasoseptal (Hadad) flap. Control CT and MRI cerebral scans showed progressive resorption of the pneumocephalus with the nasoseptal flap covering the bony defect (C).

cortical bone erosion and adjacent soft tissue swelling. The MRI findings are replacement of clival fatty bone marrow by exudate and effacement of soft tissues, resulting in a marked drop of T1-weighted signal in pre-contrast images. The soft tissues and bones involved are greatly enhanced with contrast medium ${ }^{10}$.

Osteoradionecrosis, a possibly lethal complication of radiation therapy (RT) ${ }^{24}$, can develop in the skull base (Fig. 2). In addition to neoplastic cells, RT damages healthy cells of the vascular endothelium, this creates the pathogenetic triad of hypoxia, hypocellularity, and hypovascularity. Type II diabetes mellitus, smoke and vascular diseases are considered possible risk factors. Among head and neck malignancies, RT for nasopharyngeal carcinoma is the main responsible for osteoradionecrosis ${ }^{25,26}$.

It is important to mention spontaneous clival CSF leaks ${ }^{27}$ (Fig. 3). The diagnosis is made through beta-2-transferrin testing, CT scan and MRI. As reported by Van Zele et al., transclival meningoceles and spontaneous CSF leaks located at the clivus are extremely rare entities ${ }^{28,29}$. 


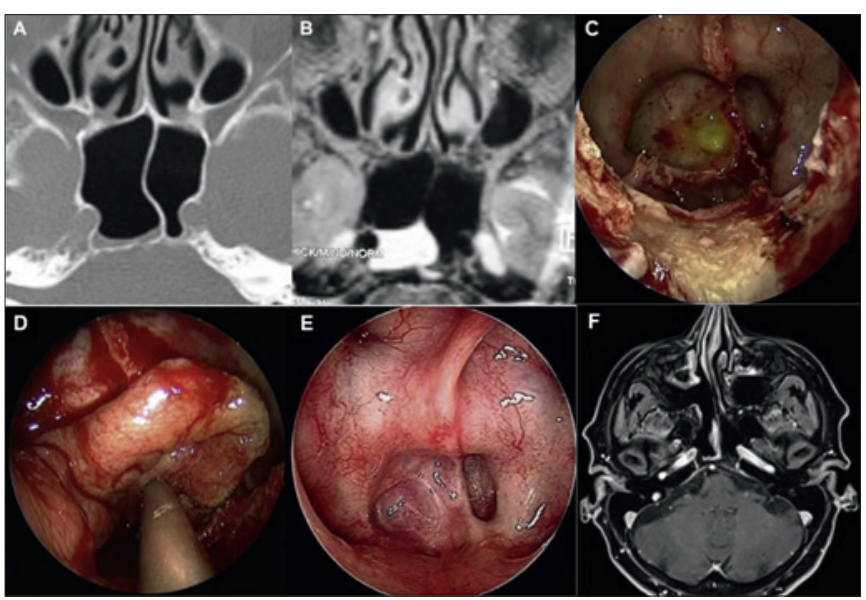

Figure 3. Computed tomography (A) and T2-weighted MRI (B) in a patient with a right clival spontaneous cerebrospinal fluid leak. Intraoperative endoscopic view showing a paraseptal approach: the sphenoidotomy is enlarged to gain adequate access to the sinus, and the intersinusal septum is drilled out. The cerebrospinal fluid leak with small meningocele can be clearly identified in the posterior wall of the sphenoid. The green colouration is due to the intraoperative use of fluorescein (C). Intraoperative view of the nasoseptal flap placed overlay within the posterior wall of the sphenoid sinus, covering the clival area (D). Endoscopic endonasal view 24 months after surgery (E) and postoperative axial T1-weighted MRI scan with gadolinium showing a nasoseptal flap covering the clival area on the right sphenoid sinus $(\mathbf{F})$.

Fractures of the clivus are not uncommon and have been reported in $0.2 \%$ of patients with head injuries and in $2 \%$ of patients with skull fractures ${ }^{10}$. They can be classified as three types: sagittal (intersecting the dorsum sellae), transverse (intersecting both petrous ridges) and oblique (intersecting one petrous ridge). Oblique fractures are the most common, while patients with a transverse fracture have the highest risk of death ${ }^{30}$.

\section{Surgical approaches}

The chapter of surgical approaches to the clivus and the craniovertebral junction (CVJ) is still a field of study and open debate: the major certainty is that there isn't a common and univocal endorsement among expert with regard to the best approaches to manage the clivus yet. The paths described to reach clival pathologies are many; the main division is between the endoscopic transnasal transclival approaches (ETCAs) and microsurgical transcranial approaches (MTCAs). Below the table with all the current approaches to the clivus (Tab. II).

Surgery of the lateral skull base has developed in the last 50 years, starting from the traditional transcranial microsurgery. At the same time, different anterior extracranial and transclival approaches have been described and applied, characterized by "waves" with a progressive rise and fall of new procedures ${ }^{31}$. These were initially described with enthusiasm, they might have become widely used, but then fell into disuse after reports of complications, like transcervical and transoral approaches.

Endoscopic transnasal skull base surgery started in the last 25 years, also addressing clival pathologies, with increasing relevance. Since then, the endoscopic transnasal transclival approach has been widely accepted for extradural pathologies, mainly clival chordomas, but its use remains highly debated for intradural lesions due to the issue of dural and skull base reconstruction and the high rate of postoperative CSF leak (Fig. 4).

According to Bossi Todeschini et al. the advantages that make the endoscopic transclival approach a promising technique to treat midline posterior fossa pathologies consist in avoiding cerebral retraction, near-field magnification, better surgical field illumination, minimal manipulation of neurovascular structures, and direct access to the tumor as well as early access to its vascular supply and the possibility of removing the involved bone and/or dura ${ }^{32}$.

Belotti et al. published an interesting historical overview about transclival approaches for intradural pathologies, the results showed an initial preponderance of vascular pathologies, mainly posterior circulation aneurysms and some cavernous malformations of the brainstem. Intradural

Table II. Surgical approaches to the clivus.

Endoscopic transnasal transclival approaches (ETCAs)

Transnasal ETCA

ETCA with intradural hypophysiopexy (pituitary transposition)

ETCA with far-medial extension (ETCA-FM)

Aterolateral Microsurgical Transcranial Approaches (MTCAs)

Supraorbital approach (SO)

Mini-pterional approach (MPT)

Pterional approach (PT)

Pterional transzygomatic approach (PTTZ)

Fronto-temporal-orbito-zygomatic approach (FTOZ)

Lateral Microsurgical Transcranial Approaches (MTCAs)

Subtemporal approach (ST)

Subtemporal transzygomatic approach (STTZ)

Posterolateral Microsurgical Transcranial Approaches (MTCAs)

Retrolabyrinthine approach $(\mathrm{RL})$

Translabyrinthine approach (TL)

Transcochlear approaches (TC)

Retrosigmoid approach

Infratemporal approaches (type A, B, C, D)

Petro-occipital transigmoid approach (POTS)

Far-lateral approach

Extreme-lateral approach 


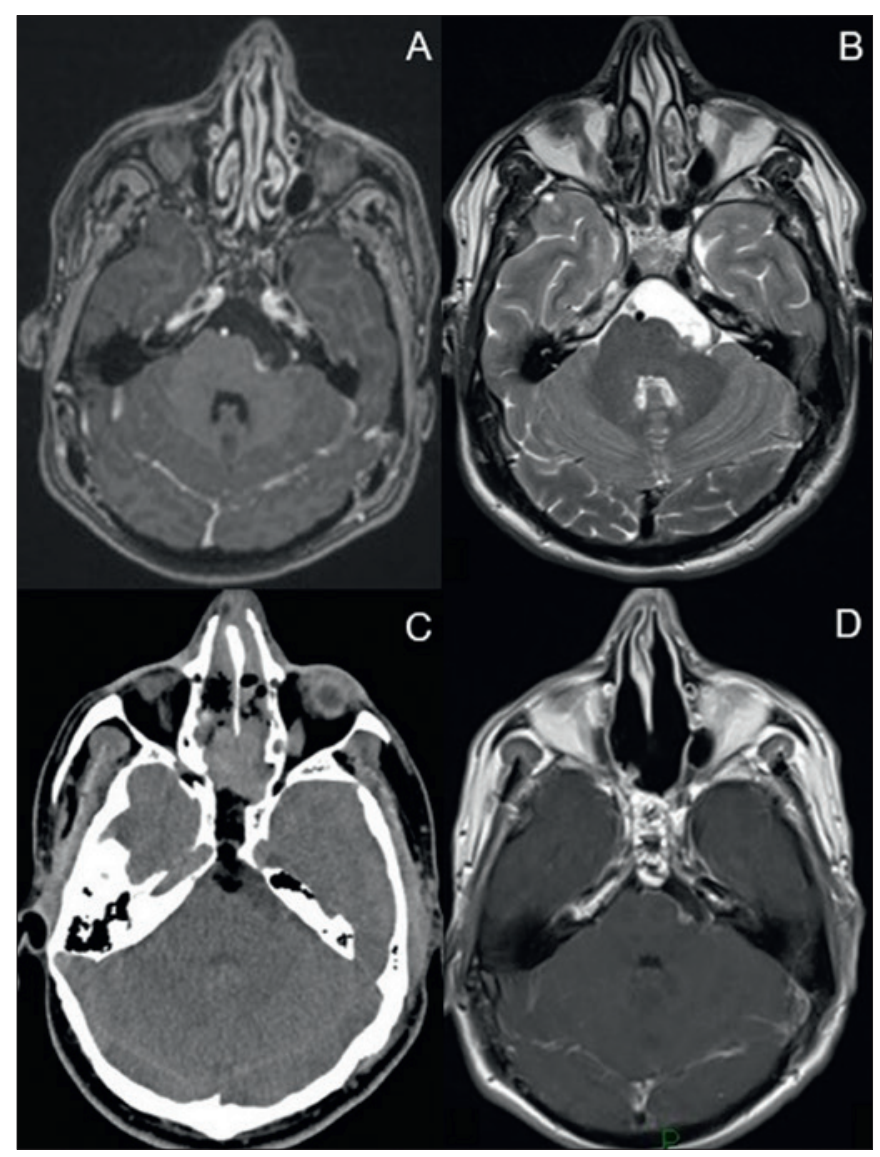

Figure 4. Images of a 35-year-old man admitted with left trigeminal (V1V2) palsy, dizziness, left ear hearing loss. MRI revealed a large cystic lesion of the left cerebellopontine cistern with posterior displacement of the fifth left cranial nerve and a possible small post-contrast impregnation of a portion of the medial wall (A, B). Head CT scan showed the surgical result (C) after an endoscopic transsphenoidal/transclival approach performed with the complete macroscopical removal of the lesion, that presented as a large cyst with a thin layer of white capsule containing soft white tissue. A dural plastic with autologous fat, an intradural layer of fascia lata and a septal flap followed, as shown in postoperative MRI (D). The results of the histological tests reported aspects indicative of a primary squamous cell carcinoma ${ }^{42}$ (this article is distributed under the terms of the Creative Commons AttributionNon CommercialShare Alike 4.0 License).

pathologies, including meningiomas, schwannomas, epidermoid cysts and neurenteric cysts were reported sporadically in the 1990s and showed a significant increase since 2005, parallel with the evolution of transnasal endoscopy. The main boost to the widespread use of endoscopic transclival approaches was most probably the introduction of this technique for the treatment of clival chordomas ${ }^{31}$. This rise has gone together with the refinement of skull base reconstruction techniques and materials from autologous flaps, fat, fascia, cartilage and bone, to synthetic materials as fibrin glue, lyodura, collagen matrix, oxidized cellulose and gelatin sponge.
There is an increasing number of published works that give growing importance to the anterior transclival approaches in terms of comparable gross total resection (GTR) rates compared to the transcranial approaches ${ }^{33}$. As regards possible complications, CSF leak rate was higher in midline approaches, in contrast to postoperative cranial nerve palsy, which was higher in lateral approaches.

There are still some limitations to exclusive transclival approaches, according to other experts opinion, like the management of lesions that further extend laterally to the cranial nerves plane, and midline tumors having a very limited inter-carotid distance with a high risk of ICA rupture and inadequate lesion exposition. According to La Corte et al. such cases should benefit from a combined (one or multi-staged) approach or a lateral TCA to avoid tumor removal between cranial nerves and therefore reduce the risk of postoperative deficits, and to avoid working through a narrow corridor between the ICAs at different segments ${ }^{34}$. Staged surgery is a viable option when using combined approaches, such as extensive extradural surgery followed by the removal of the intradural tumor, with a view to prevent the risk of CSF leak.

An interesting preclinical anatomical study was made by Agosti et al. in order to establish possible advantages of endoscopic approaches in relation to the exposure of lateral structures ${ }^{35}$. ETCAs objectively provide an advantage in terms of clival exposure, when compared with MTCAs. A statistically significant gain of exposure of the lateral anatomical structures and jugular tubercles was offered by ETCAs with far-medial extension (ETCA-FM), that include the exposure of the neurovascular pterygoid structures, Eustachian tube transposition, drilling of the anteromedial portion of the ipsilateral occipital condyle and the medial portion of the jugular tuberculum, identifying the lower cranial nerves ${ }^{36}$.

Minghao et al. believe that ETCA-FM approach provides the greatest surgical exposure at the lower clivus, but provides limited lateral exposure and surgical freedom. The Extreme-Lateral approach provides the greatest surgical exposure at the lower clivus among the craniotomy approaches but carries a greater risk of damage to neurovascular structures and increased operative time ${ }^{37}$.

Despite these data, it is important to note that, as preclinical studies, these works did not consider the possible increase in working volume and anatomical distortion caused by a space-occupying lesion nor the position of relevant vascular and neural structures in relation to the mass. For such reasons, no surgical approach can be recommended over another based on a preclinical study alone ${ }^{35}$.

Recent studies of cadaveric dissection are testing new combined and hybrid approaches, that are more in the field 
of neurosurgery, like a hybrid anterolateral transcondylar approach to evaluate the use of endoscope-assisted micro neurosurgery through an anterolateral approach ${ }^{38}$. This approach provides lateral access to the cervical spine and craniovertebral joint (CVJ) from C6 to the foramen magnum with early control of the extradural vertebral artery and the major venous structures. The greatest advantage showed by this study is the extension of the surgical corridor to the middle and upper clivus up to the sphenoid sinus. Combining classical microsurgical techniques with the keyhole endoscope-assisted concept a complete resection is achieved, using a single operative corridor rather than combining endoscopic endonasal and anterolateral approaches. Reviewing literature and published experiences, the conclusion is that many variables must be considered when surgery is planned ${ }^{39}$ : which is the part of the clivus involved (superior, middle or inferior part), which is the pathology with regard to the histology, the lateral extension and the structures involved; the anatomy of the patient; previous treatments and need for further therapies; comorbidities.

The surgical approach, therefore, shouldn't be chosen aprioristically but based on a patient-centred analysis. Moreover, the combination of multiple surgical corridors, one complementary to another, allows the surgeon to work around the relevant anatomy and to avoid dissection passing the plane of cranial nerves. With this principle, the optimization of the resection and the decrease of morbidity is achieved, also when facing big tumors involving the $\mathrm{CVJ}{ }^{40,41}$.

\section{Conclusions}

From diagnosis to surgery and medical treatment, clival pathologies require the multidisciplinary management of ENT surgeon and neurosurgeon, whose partnership is fundamental, but also neuroradiologist and, when needed, anatomopathologist, radioterapist, oncologist and infectious diseases specialist. Sharing of expertise is the advisable way to ensure the best standard of treatment and higher survival rate to aggressive and recurrent diseases with potential lethal course and complications.

\section{References}

1 Samii M, Knosp E. Approaches to the clivus. Approaches to no man's land. Berlin Heidelberg: Springer-Verlag; 1992. pp. 1-6.

2 Jinkins JR. Atlas of neuroradiologic embryology, anatomy, and variants. Philadelphia: Lippincott Willams \& Wilkins; 2000. pp. 63-65, $100,116,732$.

3 Dileva A, Bruner E, Haider T, et al. Skull base embryology: a multidisciplinary review. Childs Nerv Syst 2014;30:991-1000. https://doi. org/10.1007/s00381-014-2411-x

4 Rai R, Iwanaga J, Shokouhi G, et al. A comprehensive review of the clivus: anatomy, embryology, variants, pathology, and surgi- cal approaches. Childs Nerv Syst 2018;34:1451-1458. https://doi. org/10.1007/s00381-018-3875-x

5 Destrieux C, Velut S, Kakou MK, et al. A new concept in Dorello's canal microanatomy: the petroclival venous confluence. J Neurosurg 1997;87:67-72. https://doi.org/10.3171/jns.1997.87.1.0067

6 McMaster ML, GoldsteinAM,Bromley CM, etal.Chordoma: incidence and survival patterns in the United States, 1973-1995. Cancer Causes Control 2001;12:1-11. https://doi.org/10.1023/a:1008947301735

7 Walcott BP, Nahed BV, Mohyeldin A, et al. Chordoma: current concepts, management, and future directions. Lancet Oncol 2012;13:e6976. https://doi.org/10.1016/S1470-2045(11)70337-0

8 Neelakantan A, Rana AK. Benign and malignant diseases of the clivus. Clin Radiol 2014;69:1295-1303. https://doi.org/10.1016/j. crad.2014.07.010

9 Ditzel Filho LFS, Prevedello DM, Dolci RL, et al. The endoscopic endonasal approach for removal of petroclival chondrosarcomas. Neurosurg Clin N Am 2015;26:453-462. https://doi.org/10.1016/j. nec.2015.03.008

10 Hofmann E, Prescher A. The clivus anatomy, normal variants and imaging pathology. Clin Neuroradiol 2012;22:123-139. https://doi. org/10.1007/s00062-011-0083

11 Mohyeldin A, Prevedello DM, Jamshidi AO, et al. Nuances in the treatment of malignant tumors of the clival and petroclival region. Int Arch Otorhinolaryngol 2014;18(Suppl 2):S157-172. https://doi. org/10.1055/s-0034-1395267

12 Dekker SE, Wasman J, Yoo KK, et al. Clival metastasis of a duodenal adenocarcinoma: a case report and literature review. World Neurosurg 2017;100:62-68. https://doi.org/10.1016/j.wneu.2016.12.078

13 Cathel A, Khan YR, Blais D, et al. Metastatic disease to clivus: biopsy or not? Cureus 2019;11:e5658. https://doi.org/10.7759/cureus.5658

14 Pallini R, Sabatino G, Doglietto F, et al. Clivus metastases: report of seven patients and literature review. Acta Neurochir (Wien) 2009;151:291-296; discussion 296. https://doi.org/10.1007/ s00701-009-0229-1

15 Amita R, Sandhyamani S, Nair S, et al. Plasmacytoma of the clivus. Asian J Neurosurg 2017;12:573-575. https://doi. org/10.4103/1793-5482.148788

16 Lee J, Kulubya E, Pressman BD, et al. Sellar and clival plasmacytomas: case series of 5 patients with systematic review of 65 published cases. Pituitary 2017;20:381-392. https://doi.org/10.1007/ s11102-017-0799-5

17 Emanuelli E, Ciorba A, Bianchini C, et al. Transnasal endoscopic management of petrous apex and clivus selected lesions. Eur Arch Otorhinolaryngol 2013;270:1747-1750. https://doi.org/10.1007/ s00405-012-2229-7

18 Hoa M, House JW, Linthicum FH, et al. Petrous apex cholesterol granuloma: pictorial review of radiological considerations in diagnosis and surgical histopathology. J Laryngol Otol 2013;127:339-348. https://doi.org/10.1017/S0022215113000091

19 Jackler RK, Cho M. A new theory to explain the genesis of petrous apex cholesterol granuloma. Otol Neurotol 2003;24:96-106; discussion 106. https://doi.org/10.1097/00129492-200301000-00020

20 Sanna M, Saleh E, Khrais T, et al. Atlas of microsurgery of the lateral skull base. Second Edition. New York: Thieme; 2007.

21 Heman-Ackah SE, Boyer H, Odland R. Clival fibrous dysplasia: case series and review of the literature. Ear Nose Throat J 2014;93:e4-9. https://doi.org/10.1177/014556131409301202

22 Lagman C, Varshneya K, Sarmiento J, et al. Proposed diagnostic criteria, classification schema, and review of literature of notochord- 
derived ecchordosis physaliphora. Cureus 2016;8:e547. https://doi. org/10.7759/cureus.547

${ }^{23}$ Georgalas C, Terzakis D, Tsikna M, et al. Ecchordosis physaliphora: a cautionary tale. J Laryngol Otol 2020;134:46-51. https://doi. org/10.1017/S0022215119002512

24 Daoudi H, Labeyrie MA, Guillerm S, et al. Multimodal strategy for the management of sphenoid osteoradionecrosis: preliminary results. Laryngoscope Investig Otolaryngol 2020;5:19-23. https://doi. org/10.1002/lio2.345

25 Han P, Wang X, Liang F, et al. Osteoradionecrosis of the skull base in nasopharyngeal carcinoma: incidence and risk factors. Int J Radiat Oncol Biol Phys 2018;102:552-555. https://doi.org/10.1016/j. ijrobp.2018.06.027

26 Risso A, Zoia C, Gianformaggio C, et al. Tension pneumocephalus secondary to osteoradionecrosis of the clivus. Rep Pract Oncol Radiother 2016;21:71-75. https://doi.org/10.1016/j.rpor.2015.05.007

27 Pagella F, Pusateri A, Matti E, et al. Endoscopic management of spontaneous clival cerebrospinal fluid leaks: case series and literature review. World Neurosurg 2016;86:470-477. https://doi.org/10.1016/j. wneu.2015.11.026

28 Van Zele T, Kitice A, Vellutini E, et al. Primary spontaneous cerebrospinal fluid leaks located at the clivus. Allergy Rhinol (Providence). Summer 2013;4:e100-104. https://doi.org/10.2500/ar.2013.4.0053

29 Panagopoulos D, Themistocleous M, Sfakianos G. Repair of a transclival meningocele through a transoral approach: case report and literature review. World Neurosurg 2019;123:259-264. https://doi. org/10.1016/j.wneu.2018.12.025

30 Winkler-Schwartz A, Correa JA, Marcoux J. Clival fractures in a level I trauma center. J Neurosurg 2015;122:227-235. https://doi. org/10.3171/2014.9.JNS14245

31 Belotti F, Tengattini F, Mattavelli D, et al. Transclival approaches for intradural pathologies: historical overview and present scenario. Neurosurg Rev 2021;44:279-287. https://doi.org/:10.1007/ s10143-020-01263-w

32 Bossi Todeschini A, Montaser AS, Hardesty DA, et al. The limits of the endoscopic endonasal transclival approach for posterior fossa tumors. J Neurosurg Sci 2018;62:322-331. https://doi.org/10.23736/ S0390-5616.18.04411-9

33 Patra DP, Hess RA, Turcotte EL, et al. Surgical outcomes with mid- line versus lateral approaches for cranial base chordomas: a systematic review and meta-analysis. World Neurosurg 2020;140:378-388. e2. https://doi.org/10.1016/j.wneu.2020.03.192

34 La corte E, Broggi M, Bosio L, et al. Tailored surgical strategy in clival chordomas: an extraordinary selection bias that limits approach comparison. J Neurosurg Sci 2018;62:519-521. https://doi. org/10.23736/S0390-5616.17.03986-8

35 Agosti E, Saraceno G, Qiu J, et al. Quantitative anatomical comparison of transnasal and transcranial approaches to the clivus. Acta Neurochir (Wien) 2020;162:649-660. https://doi.org/10.1007/ s00701-019-04152-4

36 Simal-Julián JA, Miranda-Lloret P, Beltrán-Giner A, et al. Full endoscopic endonasal extreme far-medial approach: eustachian tube transposition. J Neurosurg Pediatr 2013;11:584-590. https://doi. org/10.3171/2013.1.PEDS12462

37 Wang M, Chae R, Shehata J, et al. Comparative analysis of the subtonsillar, far-lateral, extreme-lateral, and endoscopic far-medial approaches to the lower clivus: an anatomical cadaver study. World Neurosurg 2019;127:e1083-e1096. https://doi.org/10.1016/j. wneu.2019.04.048

38 Di Carlo DT, Voormolen EHJ, Passeri T, et al. Hybrid antero-lateral transcondylar approach to the clivus: a laboratory investigation and case illustration. Acta Neurochir (Wien) 2020;162:1259-1268. https:// doi.org/10.1007/s00701-020-04343-4

39 Zanoletti E, Mazzoni A, Martini A, et al. Surgery of the lateral skull base: a 50-year endeavour. Acta Otorhinolaryngol Ital 2019;39(SUPPL. 1):S1-S146. https://doi.org/10.14639/0392-100X-suppl.1-39-2019

40 Locatelli D, Karligkiotis A, Turri-Zanoni M, et al. Endoscopic endonasal approaches for treatment of craniovertebral junction tumours. Acta Neurochir Suppl 2019;125:209-224. https://doi. org/10.1007/978-3-319-62515-7_30

41 Martínez-Pérez R, Silveira-Bertazzo G, Rangel GG, et al. The historical perspective in approaches to the spheno-petro-clival meningiomas. Neurosurg Rev 2021;44:51-60. https://doi.org/10.1007/ s10143-019-01197-y

42 Pisano P, Lombardi F, Bongetta D, et al. Primary intracranial squamous cell carcinoma with a fatal course. Asian J Neurosurg 2020;15:722725. https://doi.org/10.4103/ajns.AJNS_148_20 